\title{
A educação no cenário pandêmico: o que dizem os professores da educação básica sobre o retorno às aulas presenciais
}

\author{
Education in the pandemic scenario: what basic education teachers' say about \\ returning to on-site classes
}

Rosane Barreto Ramos dos Santos

Doutoranda na Fundação Instituto Oswaldo Cruz - IOC/ FIOCRUZ no Programa de Ensino em Biociências e Saúde

heraldinocsjunior@yahoo.com.br

\begin{abstract}
Paulo Pires de Queiroz
Professor da Faculdade de Educação na Universidade Federal Fluminense - UFF/RJ ppqueiroz@yahoo.com.br
\end{abstract}

Resumo: O trabalho apresenta o contexto da educação em tempos de pandemia pelo novo coronavírus. A pesquisa trouxe como objetivo geral: analisar os efeitos da pandemia no trabalho docente e como objetivos específicos: compreender a perspectiva dos educadores sobre as práticas educativas surgidas no contexto da pandemia e investigar alternativas pedagógicas para o retorno das aulas presenciais. Configurou-se como uma pesquisa qualitativa que utilizou o recurso da análise de conteúdo para o tratamento dos dados coletados nos 69 questionários aplicados aos professores da educação básica refletindo sobre o ensino remoto, a saúde mental docente $\mathrm{e} o$ retorno às aulas presenciais. Os resultados encontrados apontam para as dificuldades dos atos de ensinar e a urgência de medidas eficazes de prevenção que garantam um retorno seguro às atividades escolares.

Palavras-chave: Pandemia; Ensino Remoto; Saúde Mental Docente.

\begin{abstract}
The paper presents the context of education in pandemic times by the new coronavirus. The research had as its general objective: to analyze the effects of the pandemic on teaching work and as specific objectives: understand the educators' perspective on educational practices that arose in the context of the pandemic and investigate pedagogical alternatives for the return to on-site classes. It was based on the content analysis methodology with a qualitative approach, was applied a questionnaire to 69 basic school teachers seeking to reflect on remote teaching, teacher's mental health and the return to classes in school. The results found that point to the difficulties of the learning and teaching acts and the urgency of effective preventive measures that guarantee a safe return to school activities.
\end{abstract}

Keywords: Pandemic; Remote Teaching; Teacher's Mental Health. 


\section{Introdução}

A educação foi um dos setores mais impactados pelo advento da Covid-19. É necessário conhecer mais profundamente como as situações de trabalho na escola se (re) desenharam diante de situações nunca experienciadas no século XXI. Abriu-se um ambiente educacional novo para a maioria dos docentes e alunos e com isso surgiram problemas, desafios e novos conhecimentos epistemológicos e tecnológicos foram requisitados. Dos profissionais da educação, foi exigida a reinvenção de teorias e práticas no processo de ensino-aprendizagem e dos alunos, a difícil tarefa de conseguirem cumprir com os conteúdos prescritivos, mesmo sem ter, muitas vezes, as condições tecnológicas para tal.

Nesse sentido, é importante ampliarmos as questões que envolvem a escola na atual situação pandêmica de restrições sociais e as discussões sobre o retorno às atividades escolares presenciais, sob a ótica dos professores da educação básica. A percepção desses profissionais, cujos obstáculos e enfrentamentos foram vivenciados intensamente ao longo da aplicação das novas configurações de suas práticas laborais, possui inestimável contribuição e deve ser levada em consideração no planejamento acerca do novo (re)começo escolar.

Diante das conjecturas oriundas do contexto pandêmico, podemos levantar os seguintes questionamentos: Que tipo de trabalho educativo foi possível desenvolver durante o período de fechamento das escolas? Foi possível desenvolver um trabalho de qualidade nesse processo? Houve situações que tornaram evidentes os abismos sociais entre ricos e pobres? Quais principais limites, dificuldades e desafios os educadores se defrontaram durante seu trabalho? Quais premissas foram priorizadas e o que foi necessário deixar de lado, para a construção de uma realidade jamais imaginada? Em quais condições podemos retornar as atividades presenciais nas escolas?

As questões acima relacionadas giram em torno da seguinte problemática: "Como a pandemia da Covid-19 transformou as práticas educacionais?”. A fim de responder o problema proposto, a pesquisa trouxe como objetivo geral: analisar os efeitos da pandemia no trabalho docente e como objetivos específicos: compreender a perspectiva dos educadores sobre as práticas educativas surgidas no contexto da pandemia e investigar alternativas pedagógicas para o retorno das aulas presenciais.

Com base nesses questionamentos, o trabalho dividiu-se em três capítulos, onde refletimos o cenário pandêmico, a educação frente aos desafios da Covid-19 e as 
orientações da Nota Técnica n ${ }^{\circ}$ 1/2020 do Instituto Oswaldo Cruz (IOC/Fiocruz) para um retorno seguro às aulas presenciais. A revisão bibliográfica é sustentada pelos resultados de uma pesquisa qualitativa que contou com um questionário on-line fechado como instrumento de compreensão das impressões de 69 professores da educação básica acerca de suas realidades de trabalho durante a pandemia.

Com a análise de conteúdo de Bardin (2011) foi possível codificar os dados com uma delimitação temática utilizando-se as categorias: professor, tecnologia, saúde mental e escola. Os resultados apontam para a urgência de serem repensadas práticas educacionais que respaldem e suportem o trabalho docente além de sensibilizarem nossos olhares para a realidade do cotidiano da escola básica.

\section{A pandemia da Covid-19: breve panorama}

A pandemia da Covid-19 causada pelo Coronavírus da Síndrome Respiratória Aguda Grave 2 (SARS-CoV-2) afetou bruscamente diversos setores da sociedade. Incialmente, considerada epidêmica em dezembro de 2019, os esforços para conter a disseminação do vírus não tiveram sucesso. De surto epidêmico, a Covid-19 tornou-se reconhecidamente pandêmica pela Organização Mundial da Saúde (OMS) em 11 de março de 2020.

A necessidade de convivência entre os pares e a comunicação que se faz presente no cotidiano das práticas da vida em sociedade corroboraram para a disseminação da doença o que, de acordo com Who (2020); (LIMA et al., 2020), fez com que ela se tornasse altamente transmissível. Na tentativa de conter o avanço do vírus foram determinadas algumas medidas limitando o direito de ir e vir dos cidadãos. Estratégias como isolamento e distanciamento social foram aplicadas evitando a concentração de muitas pessoas em um mesmo espaço reduzido (REIS-FILHO e QUINTO, 2020).

Apesar de todas as medidas de contenção, os números iniciais do Coronavírus indicavam, segundo dados da Johns Hopkings University \& Medicine-JHU (2021), que em 13 de março de 2020 havia 99 casos de Covid-19 confirmados no Brasil; em oito de abril de 2020, quase 1 mês depois do início da pandemia, registrávamos 2.136 pessoas contaminadas. Em dados atualizados em 29 de março de 2021, chegávamos ao espantoso número de 312.206 mortes e 12.534.688 casos confirmados. Os números alarmantes apontavam para a necessidade de reinvenção de práticas sociais a fim de mitigar a doença, exigindo para a sobrevivência do ser humano, seu afastamento do espaços coletivos. 


\section{Do ensino remoto ao retorno às aulas presenciais: a educação em um contexto pandêmico}

A escola foi uma das esferas sociais que mais sofreu com os impactos repentinos da suspensão temporária de suas atividades educativas e sociais, a partir da segunda quinzena de março de 2020 no Brasil. De acordo com a Unesco (2020), o fechamento das escolas e universidades deixou sem aulas mais de $70 \%$ dos alunos ao redor do mundo. Tal medida visava conter a propagação do vírus devido ao seu nível de transmissibilidade e a alta concentração de pessoas que frequentava o espaço escolar por longos períodos do dia, combinação propulsora para o aumento dos índices de contaminação.

Com a suspensão das aulas presenciais, o surgimento do ensino remoto emergencial respondeu aos anseios pela continuidade da aprendizagem fora do espaço escolar, momento em que de acordo com Berg et al. (2020) a educação passa a ser uma responsabilidade compartilhada pela família, pelo aluno, pelos professores com o suporte das tecnologias virtuais que em seu conjunto desempenham a função escolar. Essas mudanças educacionais temporárias, pensadas para enfrentar a crise causada pelo vírus, encontravam-se ancoradas em decretos e legislações voltadas para nortear a aplicação das novas metodologias e práticas de atividades pedagógicas com a utilização dos meios digitais.

Em se tratando de tecnologias, as aulas puderam ter continuidade mediadas pelo ensino remoto emergencial, que foi orientado por documentos como o Parecer CNE/CP $n^{\circ} 5 / 2020$ que norteava a reorganização do calendário escolar, em decorrência da emergência de saúde pública. Esse Parecer estabeleceu normas excepcionais autorizando o funcionamento de aulas remotas via internet desde a educação infantil até o ensino médio.

Essa saída emergencial se tornou uma alternativa educacional (em muitos casos, a única) para que não se perdesse o vínculo entre escola, aluno e conhecimento (BRASIL, 2020; UNESCO, 2020) e tentar cumprir os conteúdos básicos das grades curriculares dentro do período de pandemia. Porém, como afirma Costa (2020), esse tipo de ensino necessita da utilização de recursos tecnológicos e precisa estar adaptado à realidade tecnológica de cada aluno para que se realize e é nesse sentido, que o ensino remoto se tornou desafiador para diversos sistemas educacionais. Embora tenha caráter temporário, 
durante o período de sua aplicação, corroborou para realçar as diferenças da educação entre os alunos da escola pública e a privada.

A proposta de um ensino remoto emergencial, de continuidade dos estudos em tempos de isolamento e distanciamento social, revelou (ou confirmou) as desigualdades sociais que já eram conhecidas. A diferença de acesso aos estudos remotos entre alunos das escolas públicas e os da rede privada mostrou o abismo que existe entre o que se configura como a teoria e a realidade social, política e econômica desses dois mundos (ALMEIDA, DIAS e PINTO, 2020).

De acordo com Torkarina (2020) em reportagem ao Jornal Agência Brasil, segundo um levantamento de maio de 2020 feito pelo Centro Regional de Estudos para o desenvolvimento da Sociedade da Informação (Cetic.br) e solicitado pelo Unicef para medir a quantidade de crianças e adolescentes que estão sem acesso à internet e que estão com a aprendizagem prejudicadas, o Brasil possui um quantitativo de 4,8 milhões de crianças e adolescentes na faixa etária de 9 a 17 anos que não tem acesso à internet em casa. Dados de uma pesquisa da defensoria pública do Estado do Rio de Janeiro, divulgado pelo canal de notícias G1 em janeiro de 2021, apontam que mais da metade (54\%) dos alunos de todo o estado do Rio de Janeiro enfrentam problemas de acesso à internet e que $10 \%$ dos alunos não dispõem de nenhum tipo de conexão.

Os dados acima comprovam a realidade enfrentada por inúmeros alunos e professores das escolas públicas. Complementam Berg, Vestena e Costa-Lobo (2020) que além da dificuldade de acesso, a transferência do espaço escolar para o ambiente doméstico causou transtornos na vida de alunos e seus responsáveis e dos professores. Situações como falta de alimentação, pois os alunos de baixa renda, por vezes, só conseguiam acesso à alimentação de qualidade dentro da escola; o despreparo dos professores para o ensino virtual; falta de acesso aos aparelhos que suportassem as atividades enviadas virtualmente; sensação de isolamento tanto de alunos quanto de professores são alguns dos exemplos que podem ser analisados nessa transposição do espaço escolar para o interior das residências dos alunos.

Trazendo o enfrentamento pandêmico para o contexto educacional, podemos afirmar juntamente com Santos (2020), Berg, Vestena e Costa-Lobo (2020) que os indicativos da dificuldade de acesso à educação de qualidade pelos mais pobres através dos recursos educacionais já era latente mesmo antes da pandemia. O que se alargou ao longo do período pandêmico foram os abismos econômico, social, político e educacional que destacaram os desafios individuais e coletivos da humanidade, revelando o abismo 
de oportunidades de aprendizagem aos quais os alunos foram expostos nessa realidade pandêmica (ALMEIDA, DIAS e PINTO, 2020).

Segundo Santos (2020), essa falta de oportunidades iguais para as diferentes classes sociais pode ser considerada uma fratura social, pois expõe as fragilidades do sistema educativo brasileiro em não garantir aos estudantes das classes populares as condições básicas de acesso aos recursos pedagógicos essenciais para uma aprendizagem exitosa. Essa exclusão concorre para desfavorecer o que Szymanzki (2003) considera como o objetivo maior da educação que é o conjunto família, escola e professores interligados em prol da aprendizagem exitosa dos alunos, o que de acordo com Pereira, Santos e Manenti (2020) pode deixar sequelas para a vida inteira do indivíduo.

A reflexão crítica sobre o espaço da casa deve defrontar-se com a concepção idealizada e romântica de um lar harmonioso para incorporar importantes nuances de gênero, classe e raça, especialmente no que diz respeito ao trabalho doméstico e violência doméstica (MOREIRA et al., 2020). Complementa Mendes (2013) que as condições propícias para o bom acompanhamento das aulas remotas passam por um ambiente silencioso, tranquilo e que não seja um espaço de trânsito de pessoas, realidade contrária à vivida pela maioria das famílias das classes populares que vivem em espaços geograficamente reduzidos, dispondo de aparelhos celulares e computadores compartilhados por mais de uma pessoa ao mesmo tempo.

Moran, Masetto e Behrens (2001) destacam que uma outra grande dificuldade hoje enfrentada para o uso das tecnologias de forma eficiente pelos sistemas de ensino pode estar acampada no paradigma da escola como transmissora de conhecimentos por meio de livros, quadro negros, memorização entre outros aspectos da educação tradicional.

Impõe-se, portanto, em tempo atual extremamente instável e imprevisível, dinâmico, conectado e desigual a necessidade cada vez maior de um entendimento sistêmico educacional que não se limite apenas a transmissão de conteúdo, mas sim, produza e gere condições de cooperação, autonomia e criatividade (BERG, VESTENA e COSTA-LOBO, 2020).

Essa não valorização adequada da tecnologia como ferramenta de ensino que durante anos foi relegada a segundo plano fez-se primordial em tempos pandêmicos. Dessa forma, aproximaram-se professor, aluno e aprendizagem, o que, de acordo com Kensi (2015), fez com que a sala de aula fosse redefinida atendendo à uma evolução da tecnologia em um novo ambiente de aprendizagem: o virtual. 
O surgimento do vírus da Covid-19 não se constituiu somente como um problema de saúde coletiva. O cenário educacional alavancado pelo surgimento do vírus, além das questões supracitadas, direcionou a preocupação para a saúde emocional do atores protagonistas do processo de ensino-aprendizagem.

Vale lembrar que antes do cenário pandêmico estar instaurado, pesquisadores já apontavam para o adoecimento mental do professor da educação básica. De acordo com Pereira, Santos e Manenti (2020) segundo a Organização Internacional do Trabalho (OIT), desde 1983 a classe profissional docente é a segunda a sofrer com mais doenças ocupacionais, incluindo doenças físicas e mentais.

Para autores como Codo (2007); Carlotto (2002) e Benevides-Pereira (2002) os docentes configuram-se como uma das classes trabalhadoras que mais tem sido afetada pelo adoecimento mental devido aos fatores relacionados às atividades pedagógicas desenvolvidas. Para Tardif e Lessard (2014), o adoecimento do professor não interfere e/ou influencia somente o processo de ensino-aprendizagem, mas também a relevância de seu papel social e à escola como um todo. Seligmann-Silva (2013) complementa trazendo situações atuais que têm contribuído para que o quadro do adoecimento mental do docente seja gradativamente acentuado:

[...] várias grandes mudanças têm sido consideradas nos impactos produzidos sobre a sociogênese dos distúrbios mentais: mudanças socioambientais, [...], intensificação dos meios de transporte e de comunicação, aumento da violência em muitos contextos, poder das mídias, expansão tecnológica em geral [...] (SELIGMANN-SILVA, 2013: 212).

Com o advento da pandemia da Covid-19, as afirmações expressas pelos autores ganharam ainda mais profundidade, pois a esses fatores, foram acrescidos $\mathrm{o}$ distanciamento social de docentes e discentes, a transformação do espaço doméstico em sala de aula e a mediação das tecnologias (nem sempre eficazes) na aproximação entre sujeitos e o conhecimento escolar.

Nesse contexto de adoecimento docente, ainda pode ser acrescida uma abrupta mudança de paradigmas educacionais, a ausência dos alunos nas aulas virtuais, a sensação de que não se aprendia corretamente e não se ensinava adequadamente, a necessidade de adequação curricular e a constante incerteza quanto a um retorno presencial escolar sem as devidas estruturas básicas de funcionamento. Essas são algumas das situações que, segundo Pereira et al. (2020); Ramirez-Ortiz et al. (2020) e Bezerra et al. (2020) 
acentuaram o adoecimento psicológico dos professores da educação básica, transformando o movimento saudável de aprendizagem em algo sofrível, fazendo com que o professor se sentisse impotente frente ao não cumprimento com êxito de sua missão de ensinar, gerando quadros depressivos, de ansiedade e estresse.

[...] Estimular a solidariedade, a resiliência e a continuidade das relações sociais entre educadores e alunos nesse período é fundamental, pois ajuda a minorar o impacto psicológico negativo da pandemia nos estudantes. Agora, importa prevenir e reduzir os níveis elevados de ansiedade, de depressão e de estresse [...] (DIAS e PINTO, 2020: 547).

Como vemos, o uso do ensino remoto emergencial como forma de manter o elo entre o aluno e a escola teve seus desafios e enfrentamentos e foi vivenciado de maneiras plurais considerando-se as particularidades de cada sistema de ensino e o cotidiano de cada professor e seu grupo de alunos. As experiências vividas no âmbito educacional, ao longo do período pandêmico com suas nuances, influenciaram mudanças de comportamentos sociais, laborais e situacionais que fizeram surgir ou acentuaram elementos na saúde emocional dos professores.

As angústias expressas por professores e alunos nesse período revelaram o desejo do retorno às atividades presenciais, o que de acordo com Brait et al. (2010) confirmam que a aprendizagem depende do ambiente, das relações interpessoais construídas na aproximação entre os sujeitos. Embora os meios digitais forneçam uma forma alternativa de interação, segundo Brait et al. (2010), não atendem satisfatoriamente aos objetivos do processo de ensino-aprendizagem. Ferreira e Barbosa (2020) complementam que inclusive os professores se dedicaram durante o ensino remoto emergencial esperando o momento do retorno às suas funções no ambiente presencial.

Nesse intuito, segundo Dussel (2020), o planejamento da reabertura das escolas precisa contemplar questionamentos de quando e como reabri-las contando com a proteção integral dos sujeitos, contemplando uma readaptação de tempos, espaços e formas de aprendizagem, preocupando-se não apenas com os currículos prescritivos, mas com a saúde física e emocional de docentes e discentes.

Porém, como planejar um retorno seguro para professores e alunos? Se antes havia as incertezas e angústias nos relacionamentos professor-aluno durante o período do ensino remoto emergencial e o anseio pelo retorno às atividades presenciais, agora a preocupação recaía sobre a reorganização do sistema escolar. Era importante refletir sobre 
quais bases e procedimentos estariam alicerçados as estratégias de retorno, de acordo com a situação epidemiológica de cada região em particular.

Seria necessário, portanto, garantir a segurança de professores e alunos promovendo ações permanentes de vigilância em saúde. Outrossim, devem ser pensados novos planejamentos com metas para serem cumpridas a longo prazo, pois alerta a Unesco (2020) que os reflexos dos problemas educacionais poderão persistir por anos, pois,

[...] mesmo quando as escolas reabrirem, a emergente recessão econômica ameaça exacerbar as desigualdades e pode reverter o progresso obtido na expansão do acesso educacional e na melhoria da qualidade da aprendizagem em todo o mundo [...]. Na medida em que a humanidade procura maneiras de transformar o mundo para melhor após a pior crise de saúde em um século, nós precisamos repensar as políticas sociais, incluindo a educação, e abordar questões de longa data relacionadas à desigualdade estrutural, à pobreza e à exclusão. [...] (UNESCO, 2020).

Nesse sentido, a escola precisa ter em seu cerne o projeto de sociedade que almeja, para que seja promotora de debates sobre desigualdades, humanidades, perspectiva de futuro sem deixar de contextualizar o presente. E, dessa forma, inserindo como um dos eixos de seu projeto, uma proposta de saúde holística que considere o ser humano em sua integralidade doravante debatendo a importância da saúde para o desenvolvimento de uma educação exitosa onde ambos professores e alunos se sintam como partes indispensáveis da formação do homem como ser transformador da sociedade.

\section{A Nota Técnica no 1/2020 do IOC/FIOCRUZ como norteadora de ações para o retorno às atividades escolares presenciais}

A suspensão das atividades escolares teve por base as orientações de especialistas das áreas da saúde e da educação, a fim de minimizar os riscos da pandemia da Covid19. Com base em estudos científicos, os direcionamentos permitiram que os impactos desse afastamento fossem atenuados, para que a educação não fosse definitivamente interrompida e que a escola não se transformasse em um foco de transmissão do vírus.

Dentro de uma perspectiva de retorno presencial das atividades escolares, esses mesmos profissionais precisam ser ouvidos haja vista o papel primordial da Ciência nos caminhos epistemológicos que melhor devem ser traçados na edificação da volta segura 
às atividades educacionais. Nesse sentido, a escolha da Nota Técnica $n^{\circ} 1 / 2020$ do Programa de Pós-Graduação de Ensino em Biociências e Saúde do Instituto Oswaldo Cruz - (IOC/Fiocruz) responde à necessidade de serem construídas estratégias escolares com uma linguagem que envolva Ciência e a preocupação com o planejamento escolar, tendo por base um documento elaborado por doutores especialistas nas áreas da saúde e da educação.

Em tempos de recomeço, vários são os questionamentos levantados pela escola: quais premissas embasarão o (re)começar ou um novo começo das práticas educativas? Em um contexto de (re)invenção, como se encontrarão professores e alunos? De onde partir, como e onde conseguiremos chegar? O que mais importa nesse processo? Como estarão os alunos? O que se aprendeu e o que ficou para trás? Podemos aqui elencar várias outras reflexões que certamente tomaram conta dos pensamentos e preocupações dos profissionais da educação.

A Nota Técnica ${ }^{\circ} 1 / 2020$ apresenta possíveis respostas e sugestões de retomada das atividades escolares contemplando desde estratégias referentes às medidas de prevenção da transmissão da Covid-19, (re)organização dos espaços escolares, monitoramento e promoção da saúde. Também lança sugestões sobre práticas educacionais diferenciadas que possam atender às demandas de professores e alunos no intuito de não só preencher lacunas deixadas pelo ensino remoto, mas de proporcionar novos olhares sobre os atos de aprender e ensinar. Além disso, ocupa-se dos professores e alunos em seus aspectos cognitivos, psicológicos e emocionais. Outrossim, aponta para o diálogo com órgãos e entidades de saúde problematizando ações norteadoras para o reestabelecimento das atividades nas instituições educativas.

De acordo com a Nota Técnica $n^{\circ} 1 / 2020$ (IOC/Fiocruz), como cada escola possui sua particularidade, caberá a ela discernir sobre as ações que precisarão ser delineadas para o bom funcionamento de seu espaço favorecendo a construção “[...] de um Plano Integrado e Intersetorial Local de ações para o enfrentamento e convívio com a Covid19, com ações sanitárias e educacionais, em sintonia com o planejamento de instâncias regionais e macrorregionais e respeitando a singularidade de cada escola" (FIOCRUZ, 2020: 8).

O Plano Integrado proposto pela Nota Técnica $n^{\circ}$ 1/2020 apresenta alguns componentes essenciais que contemplam a complexidade das ações que precisam ser desenvolvidas para um retorno escolar exitoso: “(1) a preservação da saúde das pessoas 
e do ambiente; (2) as soluções educacionais para o surgimento dessa nova escola; (3) uma Comissão Interna de Saúde e Ambiente na Escola” (FIOCRUZ, 2020: 9).

A relação da saúde com a escola ganha um novo esquadro e a preocupação recai em práticas pedagógicas saudáveis que beneficiem professores, alunos e todo o corpo escolar. Os olhares precisam estar inclinados para concepções que compreendam os sujeitos integralmente, substituindo as metodologias conteudistas por um ensino híbrido e reflexivo, que promova através do diálogo, a escuta e a fala dos protagonistas do processo de ensino-aprendizagem. Esse movimento de trocas de experiências, de (re)construções epistemológicas e de convívio pode favorecer o bem-estar emocional e psicológico dos professores.

O ambiente escolar deve ser um espaço promotor de saúde planetária, criando relações dialógicas que devem assegurar a educação global, una, sistêmica, reflexiva, crítica e criativa, desenvolvendo habilidades e atitudes que valorizam a vida. Neste sentido, a escola promotora da saúde planetária visa o ensino para o desenvolvimento da cidadania planetária e pretende ser colaborativa, reconectada com a comunidade escolar, valorizando a voz de todos os integrantes do sistema escolar, sendo, portanto, uma escola que oferece diálogo de saberes (FIOCRUZ, 2020: 10).

Ou seja, o ensino para ser exitoso precisa ultrapassar as barreiras do conteudismo, da preocupação única e exclusiva com aquisição de conteúdos. Nesse sentido, o Projeto Político Pedagógico de cada unidade escolar precisa inclinar as ações educacionais para que sua identidade seja (re)criada de acordo com as situações que o cenário pandêmico nos impele a fazer e decidir.

O documento ainda prevê ações que devem ser desenvolvidas junto à comunidade escolar antes da abertura física das escolas e de qualquer retorno de atividades presenciais. Ações de "reconexão, acolhimento dos educadores, ambiência da escola, organização do cotidiano escolar e criação da comissão interna de saúde e ambiente" (FIOCRUZ, 2020: 11), compõem o quadro de iniciativas que devem ser elaboradas previamente, preparando o ambiente em seus aspectos sociais, educativos e de saúde.

Os planejamentos devem englobar a preocupação com os alunos e suas famílias, a segurança alimentar das crianças, saúde emocional e/ou mental, priorizando a saúde do trabalhador, reconstrução de vínculos afetivos de alunos e professores com o espaço escolar, respeitando as regras de higiene e sanitização, reconfiguração do espaço escolar 
pensando e planejando atividades híbridas contando com o suporte necessário para que essas atividades se realizem, adoção de um sistema de rodízio possibilitando as regras de distanciamento social (FIOCRUZ, 2020).

A Nota Técnica $n^{\circ} 1 / 2020$ IOC/Fiocruz aponta para a relevância da transformação da sociedade pelo olhar sensível e comprometido da educação em consonância com os pressupostos da saúde. Norteia ações de acolhimento psicológico tanto de seus profissionais quanto de seus alunos e responsáveis em conjunto com infraestrutura adequada, para que o processo de ensino-aprendizagem aconteça dentro dos protocolos de segurança e de saúde. Dessa forma, pode se tornar viável um retorno às atividades escolares presenciais encontrando-se alternativas plurais de aprendizagem, respeitandose as singularidades de cada espaço educativo.

\section{Metodologia}

O contexto atual da educação, causado pelo surgimento da Covid-19, fez com que os professores da educação básica enfrentassem situações adversas e buscassem alternativas para que o processo de ensino-aprendizagem não fosse interrompido. Em um cenário de incertezas educacionais, o docente precisou se reinventar e se readaptar.

Para contextualizar a impressão dos professores da educação básica acerca das situações inesperadas causadas pela Covid-19 e da possibilidade de retorno das atividades presenciais, foi escolhido como instrumento metodológico um questionário online construído no formulário Google Forms com 16 (dezesseis) questões fechadas de múltipla escolha para obtenção de respostas mais rápidas e objetivas que, segundo Marconi e Lakatos (2010), fornece ao participante uma maior flexibilização de seu tempo para responder às perguntas propostas. Acresce-se às vantagens apresentadas, a possibilidade de o questionário ter sido enviado de forma on-line via aplicativo Whatsapp, utilizando-se recursos tecnológicos, haja vista o contexto pandêmico vivenciado no momento da pesquisa.

O questionário composto por 16 questões foi respondido por 69 professores da educação básica que, antes de iniciarem o preenchimento do instrumento, consentiram que suas respostas fossem utilizadas no momento do levantamento de dados. O instrumento ficou disponível para o preenchimento durante os meses de novembro/2020 a janeiro/2021. Do total de professores que participaram, 84\% (58) lecionavam em escolas públicas e $16 \%$ (12) na rede privada de ensino. Responderam à pesquisa 
professores da educação infantil, ensino fundamental (anos iniciais e finais) e ensino médio que lecionam em escolas do estado do Rio de Janeiro.

A escolha do questionário fechado de múltipla escolha possibilitou mais informações sobre o assunto (MARCONI e LAKATOS, 2010) e contou com uma metodologia qualitativa, pois interessava compreender as realidades educacionais vividas pelos sujeitos durante a pandemia. Para analisar as respostas foi utilizada a metodologia de análise de conteúdo de Bardin (2011).

A fase de pré-análise obedeceu às regras de representatividade, homogeneidade e pertinência como fontes de informação; a exploração do material encaminhou o trabalho para a codificação feita através da delimitação temática, utilizando-se as categorias: professor, tecnologia, saúde mental e escola com base na recorrência de determinados elementos que se destacavam nas respostas dos participantes. Com a utilização desse movimento metodológico foi possível compreender mais amplamente os contextos que envolvem os sujeitos, (re)significando nosso olhar sobre as práticas educacionais em tempos pandêmicos.

\section{Analisando e discutindo os dados}

Iniciando a análise do conteúdo pela categoria: professor, o tema: experiência profissional demonstrou que a maioria dos profissionais que responderam ao questionário possuía uma vasta experiência em sala de aula: $43 \%$ trabalham há mais de 15 anos no magistério; $25 \%$ entre 10 e 15 anos; $23 \%$ entre 6 a 10 anos e apenas 9\% tinha experiência de até 5 anos de docência. Tal informação aponta para práticas pedagógicas sólidas no contexto escolar entre convergências e divergências comuns nas rotinas de qualquer profissional. Portanto, podemos inferir que situações confluentes ou adversas fazem parte da rotina desses sujeitos habituados ao cotidiano da sala de aula e as intempéries comuns nas convivências escolares. Entretanto, mesmo com toda a experiência inerente, o advento da Covid-19 posicionou-os frente a desafios outrora inimagináveis cujos vastos anos de experiência não os haviam preparado.

Os dados levantados apontaram para o impacto das bruscas mudanças das formas de convivência entre professores e alunos não somente em relação ao contato físico, cotidiano, a partilha de conteúdos programáticos, mas também, das experiências sociais. O ensino presencial tradicionalmente conteudista foi abruptamente substituído pelas 
atividades a distância, com pouco ou, dependendo da situação da escola, nenhum preparo para aplicar as novas maneiras de aprender e ensinar.

A categoria 'tecnologia', sob o tema 'utilização de recursos tecnológicos', revelou que $71 \%$ dos professores não estavam familiarizados com os recursos tecnológicos para o uso do ensino remoto emergencial e que houve grande dificuldade para entender, aprender e operacionalizar os procedimentos implementados. Os demais $29 \%$ disseram saber utilizar os computadores e celulares para fins domésticos, sem grande necessidade de recursos. Porém, para saber operar os computadores para desenvolvimento de aulas virtuais, 39\% dos professores revelaram não ter recebido nenhum curso de capacitação ou orientações detalhadas sobre as postagens das atividades e 32\% tiveram capacitação, mas, afirmaram que não foi o suficiente para esclarecer as dúvidas. Somente $29 \%$ declararam ter recebido as orientações necessárias.

O questionário revelou (ou confirmou) a frágil estrutura educacional brasileira que não se encontrava preparada para lidar com situações adversas. O surgimento da pandemia no início do ano de 2020 trouxe à tona fraturas sociais que interferiram, prejudicaram o trabalho docente e a aprendizagem dos alunos e demonstraram a urgência de uma reorganização de teorias e práticas pedagógicas que flexibilizassem tempos, espaços e conteúdos a fim de permitir que a aprendizagem aconteça de maneira efetiva nas mais diversas modalidades de ensino.

Concomitantemente aos desafios do ensino remoto, 67\% dos professores afirmaram que a quantidade de horas trabalhadas e a preparação dos materiais didáticos que precisavam ser disponibilizados nos ambientes virtuais demandavam planejamentos e estratégias para manter o interesse do aluno na participação das atividades aumentaram depois do fechamento das escolas. Apesar de todos os esforços e reinvenção do trabalho docente, para $50 \%$ dos professores, menos de $20 \%$ dos alunos cumpriam com as atividades e um dos motivos apontados foi a falta de estrutura tecnológica e acesso à internet.

Os problemas emergidos devido a urgência de um ensino remoto emergencial revelaram as fragilidades do sistema público de educação em munir tanto alunos quanto professores com uma infraestrutura adequada para que o ensino não fosse bruscamente interrompido. Falta de tecnologia adequada, de recursos financeiros tanto para professores investirem em formas mais estruturadas de enviar os conteúdos, quanto para alunos para conseguirem estudar, revelaram o desgaste emocional pelo qual grande parte deles passou (e ainda passa) durante esse processo. 
Somada à essa constatação, o tema 'adequação curricular à necessidade de ensino remoto', temos as abordagens curriculares adotadas pelas escolas que, de acordo com $70 \%$ dos docentes é de característica tradicional com ênfase na transmissão de conteúdo, que até antes da pandemia tinha o respaldo do ensino em suas bases presenciais, o que facilitava o controle e o suporte ao bom andamento das atividades. Porém, essa situação se modificou com a urgência de utilização massiva das tecnologias, inviabilizando que a mesma dinâmica do ensino tradicional se mantivesse remotamente.

Segundo os entrevistados as práticas de ensino se tornaram complicadas e até mesmo inatingíveis devido à falta de acesso tanto de alunos e professores aos recursos financeiros e tecnológicos. Outros $15 \%$ declararam que o ensino possuía características construtivistas, mas que enfrentava as mesmas condições de dificuldade de acesso e outros $15 \%$ não sabiam responder sob quais bases estavam sedimentadas a metodologia adotada pela escola.

As demandas de currículo e conteúdos das aulas presenciais precisaram ser adaptadas pelas escolas e pelos professores a fim de alcançarem minimamente a quantidade de conteúdo prevista no ensino tradicional. Nesse ínterim, $47 \%$ dos professores apontaram que estão trabalhando com conteúdo bem reduzido para não deixar de atender os alunos; 20\% apresentaram dificuldade na adaptação dos conteúdos; 19\% sentem que os conteúdos não estão sendo bem trabalhados pedagogicamente e somente $14 \%$ estão conseguindo cumprir com o conteúdo previsto no planejamento anual.

Sobre o tema 'cenário escolar da aprendizagem remota', o contexto não poderia ser mais desolador, pois de acordo com $65 \%$ dos docentes, os alunos apresentaram muita dificuldade em acompanhar as tarefas lançadas nas plataformas digitais, implantadas pelas escolas ou em seguir outros meios de tecnologia. Com isso, os professores destacaram que os discentes estavam aprendendo abaixo das expectativas para cada ano de escolaridade seguindo-se de alarmantes $22 \%$ onde os professores sinalizaram o desânimo dos alunos no desenvolvimento das atividades. Tal cenário corroborou com a opinião de 93\% dos professores que afirmaram a urgência de serem flexibilizados os currículos tanto no ensino remoto quanto no planejamento de um possível retorno presencial.

$\mathrm{Na}$ categoria 'saúde mental', o tema abordado 'estado emocional dos docentes durante o ensino remoto' se preocupou com a saúde mental dos professores diante do cenário de enfrentamentos e incertezas e da falta de subsídios suficientes para que o trabalho docente continuasse com a mesma qualidade alcançada na escola presencial. 
Observou-se a presença ou intensificação de sintomas relativos à ansiedade, depressão, angústias, e tristezas generalizadas. Foi solicitado que escolhessem três sentimentos e/ou emoções que exprimissem o momento atual, seja de ordem social ou educacional: $60 \%$ apontaram a ansiedade; $47 \%$ esgotamento emocional pelo trabalho; $36 \%$ desânimo; $32 \%$ medo e apenas $30 \%$ esperança.

O sentimento de desânimo, apontado no questionário, gera a sensação de fracasso, de estar desassistido, sentimento pelo qual passam os professores, na constatação do baixo acesso dos alunos às atividades remotas e na ansiedade presente na preocupação dos docentes em adaptar os conteúdos para atender, de alguma forma, as demandas curriculares mesmo sem ter a orientação necessária. $\mathrm{O}$ aumento de sintomas e transtornos emocionais podem ser relacionados ao confinamento, ao aumento da carga de trabalho, a necessidade do desenvolvimento de estratégias e planos de trabalho concomitantemente, além da adaptação às ferramentas digitais em um curto espaço de tempo.

A ansiedade, o esgotamento emocional, o desânimo, o medo e a esperança como os sentimentos que mais afloraram entre os professores, demonstraram que o fechamento das escolas, o isolamento e o distanciamento social tornaram o trabalho do professor solitário e angustiado por saber se o aluno, mesmo à distância, estaria aprendendo. Somou-se a esse cenário psicológico, o sentimento de fracasso ao perceber que muitas vezes o trabalho foi em vão, pois ou o aluno não tinha os recursos necessários para desenvolver as atividades ou não tinha o apoio da família para tal.

Vale salientar que, de acordo com os dados levantados, essa angústia não se extinguiria com o retorno às aulas presenciais. Para os professores participantes da pesquisa, as escolas não possuíam as estruturas adequadas para que, com segurança e os procedimentos corretos, recebessem ambos os profissionais da educação e alunos.

$\mathrm{Na}$ categoria 'escola', analisando o tema 'condições básicas para um retorno escolar seguro', os professores em sua totalidade-100\%- afirmaram que as escolas não estavam preparadas para o retorno às aulas presenciais. Dentre as justificativas apontadas incluíam-se: falta de estrutura para a adequação a essa "nova realidade" e nisso estão inseridos equipamentos tecnológicos, material de higiene e sua contínua reposição assim como a periódica higienização dos espaços; falta de saneamento básico e inclusive de água; falta de um olhar para os profissionais com comorbidades, sendo que alguns sinalizaram adoecimento psicológico com a preocupação do retorno.

Os professores demonstraram extremo interesse pela volta da prática de suas atividades. Entretanto, é sabido que em se tratando de condições de saúde e doença, no 
caso de uma pandemia, seria necessário comprometimento e determinação não só dos profissionais do chão da escola, mas também das autoridades competentes em proverem os recursos e os espaços físicos necessários para que o regresso de todos os envolvidos na escola acontecesse com segurança.

Não basta a preocupação recair sobre um processo de ensino-aprendizagem exitoso, onde professores ensinam e alunos aprendem; mas, em requerer a conscientização de que o espaço escolar é feito de subjetividades e de histórias de vida. Nesse percurso, o vínculo emocional, o sentimento de pertencimento da criança e do jovem ao espaço escolar não devem ser desconsiderados, mas nortear posicionamentos que tornem o ambiente escolar em um espaço acolhedor.

A totalidade dos professores em afirmar que as escolas não estão preparadas para um possível retorno no ano de 2021, é um alerta de que os sistemas públicos de educação não se prepararam adequadamente para receber alunos e professores e que, um retorno em condições inapropriadas pode ser uma incubadora de novos casos de Covid-19. O retorno às aulas se configura como um novo cenário de incertezas e medos, pois a estrutura que muniu as escolas privadas, não é a mesma que aguarda os profissionais da escola pública.

Ao mesmo tempo em que o cenário não é favorável a um retorno seguro, os professores terem escolhido a esperança como um dos sentimentos mais pontuados, traduzem uma das características da profissão docente que é a de não desistir de sua luta. Portanto, para que o fazer educacional aconteça apesar das adversidades, é preciso continuar concebendo a profissão docente como campo de resiliência e reinvenção.

\section{Considerações finais}

Os olhares do mundo no cenário pandêmico estão voltados para a saúde, seus profissionais e os desafios oriundos do vírus que continua assolando toda a sociedade mundial. Porém, a educação também foi profundamente abalada com as mudanças emergenciais que precisaram ser feitas, para que o ensino não fosse interrompido. Das aulas corriqueiramente presenciais, concentradas no espaço escolar para o espaço doméstico, professores precisaram se reinventar, conteúdos foram adaptados e flexibilizados para suprirem, mesmo que minimamente, a aprendizagem dos alunos que se sentiram desestimulados com a dificuldade de continuarem seus estudos. 
O ensino não podia parar. E com essa consciência, docentes e alunos ingressaram em uma jornada tecnológica por muitos outrora inimaginável, e que agora se fazia imperativa e vital para a sobrevivência dos processos de ensino-aprendizagem. Destacaram-se nesse panorama, os esforços da profissão docente para que os alunos não deixassem de ter acesso à educação - direito legalmente constituído e em cujas bases a construção de sujeitos cidadãos se edifica em sociedade.

Todavia, a urgência foi de encontro à carência. Por um lado, urgência, porque em um momento cujo cenário mundial demandava presteza nos procedimentos, ações e estratégias, pressupondo-se que as estruturas sociais estariam equilibradas e preparadas para suportar as demandas advindas do caos, o sistema escolar brasileiro fez transbordar o cenário de desigualdades estruturais entre o pobre e o rico que aprende. Por outro lado, carência, porque os recursos educativos, tecnológicos, os tempos, espaços e momentos de aprender e ensinar, destinados tanto para os professores das classes populares e quanto das camadas financeiramente privilegiadas da sociedade, relevavam a discrepância de valorização da educação destinada a cada um desses grupos.

Exemplo disso, consolidou-se diante da implementação do ensino remoto emergencial, que necessitava da utilização de internet de qualidade e equipamentos tecnológicos que pudessem formar pontes entre professor e aluno para que minimamente pudessem aprender e ensinar enquanto aguardavam o momento do retorno às atividades presenciais. Concomitantemente, a família passou a integrar efetivamente esse processo, pois a transposição do espaço escolar para o espaço doméstico revelou os novos sentidos e formatos da escola e as dificuldades das famílias em acompanharem essas mudanças.

Tais análises são apresentadas no presente estudo que revelou a dificuldade estrutural brasileira para adaptar-se a uma realidade de educação remota, devido as importantes lacunas de acesso, conhecimento e familiarização com o meio digital. Desde dificuldades em acessar a internet e plataformas digitais, falta de recursos financeiros e treinamento específico para manusear as ferramentas tecnológicas até a incerteza de que os alunos estivessem efetivamente aprendendo, foram apontadas na pesquisa como fatores que fizeram com que os professores se sentissem impotentes frente ao desânimo dos alunos com a aprendizagem a distância, sendo que muitos acabavam adoecendo psicologicamente.

Houve uma dificuldade ampliada na geração de conteúdos e recursos para os alunos, causando um excesso de trabalho inédito na prática docente. Esta sobrecarga de trabalho, somada às situações já alarmantes oriundas da própria pandemia, como reclusão, 
medo de infectar-se ou ter alguém próximo infectado, gerou nos profissionais um aumento de transtornos como estresse, ansiedade e depressão.

Tais dificuldades apontam para lacunas na preocupação com o profissional da educação e seus afazeres pedagógicos durante a pandemia. As crescentes demandas de trabalho remoto, disponibilidade de tempo que excedia os horários convencionais de trabalho e baixo retorno dos alunos sobre as atividades desenvolvidas fizeram com que o professor se sobrecarregasse intelectual e emocionalmente.

Diante do panorama desafiador, um retorno seguro às atividades escolares presenciais passa por cuidados com os profissionais da educação, em especial com os professores. Eles precisam se sentir acolhidos, transformando-se a escola em um espaço de reinvenção, onde exista uma estrutura física e emocional voltada para o cuidado com a saúde e o bem-estar dos sujeitos.

Embora a pandemia exija da escola um replanejamento de atitudes e formas de conduzir o ensino, a essência da educação não se perdeu. Porém, a pesquisa aponta que, para que essa essência seja significativa para professores e alunos, precisa contemplar os sujeitos em sua integralidade, onde a escola se converta em espaços dialógicos e os planejamentos contemplem, em primeiro lugar, os sujeitos para depois se ocuparem de currículos e conteúdos e toda a esfera burocrática que também compõe a vida escolar.

A Nota Técnica $\mathrm{n}^{\circ} 1 / 2020$, apresentada no artigo, configura-se como um documento norteador preocupado com um plano de saúde integral, que compreenda a saúde dos profissionais a partir do risco de contágio pelo coronavírus, pelos transtornos mentais também consequentes da pandemia e pela necessidade de um sistema informatizado eficiente. Além disso, apresenta um planejamento de retomada das aulas presenciais, considerando em primeiro lugar, o indivíduo em suas demandas emocionais e de prevenção da doença e, consecutivamente, o aporte necessário para que as ações de prevenção rumo a um retorno seguro aconteçam, sem que se perca a essência dos atos de aprender e ensinar, que é a convivência, o diálogo, a afetividade e a trocas de experiências.

A escola é lugar de resiliência, criatividade, humanidade, conscientização e cooperação e a pandemia da Covid-19 veio ratificar a relevância de sua existência e fortalecer os elos, por vezes fragilizados, que unem sociedade e educação. E nessa direção, a esperança, um dos sentimentos mais pontuados pelos professores na pesquisa, deve nos conduzir a ações que transformem os espaços educacionais, reorientando o pensar e o agir diante da nova realidade. 


\section{Referências bibliográficas}

ALMEIDA, Érika; DIAS, Carlos \& PINTO, Fátima (2020). A educação e a Covid-19. Ensaio: Avaliação e Políticas Públicas em Educação. v. 28, n. 108, 09 p. Disponível em: https://revistas.cesgranrio.org.br/index.php/ensaio/article/ view/2985. Acesso em: dez. 2020.

BARDIN, Laurence (2011). Análise de conteúdo. São Paulo: Edições 70.

BERG, Juliana; VESTENA, Carla Luciane Blum \& COSTA-LOBO, Cristina (2020). Creativity in Brazilian Education: Review of a Decade of Literature. Creative Education, 11, 420-433. Disponível em <https://www.researchgate.net/publication/340138328_Creativity_in_Brazilian_E ducation_Review_of_a_Decade_of_Literature>. Acesso em: mar. 2021. DOI: $10.4236 /$ ce.2020.113030.

BEZERRA, Carina et al. (2020). Impacto psicossocial do isolamento durante a pandemia de covid-19 na população brasileira: análise transversal preliminar. Revista Saúde Soc. São Paulo 29 (4), p. 1-10. Disponível em: <https://www.scielo.br/pdf/sausoc/v29n4/1984-0470-sausoc-29-04-e200412.pdf>. Acesso em: dez. 2020.

BENEVIDES-PEREIRA, Ana Maria T. (Org.) (2002). Burnout: quando o trabalho ameaça o bem-estar do trabalhador. São Paulo: Casa do Psicólogo.

BRAIT, Lilian et al. (2010). A relação professor/aluno no processo de ensino e aprendizagem. Itinerarius Reflectionis, Revista Eletrônica do Curso de Pedagogia do campus Jataí-UFG, v. 8, n. 1, jan. /jul.

BRASIL (2020). Parecer CNE/CP N 5/2020. Ministério da Educação. Conselho Nacional da Educação. Reorganização do Calendário Escolar e da possibilidade de cômputo de atividades não presenciais para fins de cumprimento da carga horária mínima anual, em razão da Pandemia da COVID-19. Diário Oficial da União, Brasília, DF, 1 jun. Disponível em: <http://portal.mec.gov.br/index.php? option=com_docman\&view=download \&alias=145011-pcp005-20\&category_ slug=marco-2020-pdf \&Itemid=30192>. Acesso em Nov. 2020

CARLOTTO, Mary Sandra (2002). A síndrome de burnout e o trabalho docente. Psicologia em Estudo, 7(1), 21-29. Disponível em: < https://www.scielo.br/j/pe/a/hfg8JKJTYFpgCNgqLHS3ppm/abstract/?lang=pt>. Acesso: mar. 2020

CODO, W. (2007). Um diagnóstico integrado do trabalho com ênfase em saúde mental. In: JAQUES, M. G.; CODO, W. (Orgs.). Saúde Mental \& Trabalho: leituras. 3 ed. Petrópolis: Vozes.

COSTA, Renata (2020). Educação remota emergencial x EaD: desafios e oportunidades. Disponível em: https://pt.linkedin.com/pulse/educa\%C3\%A7\%C3\%A3o-remotaemergencial-X-ead-desafios-e-renata-costa. Acesso em: jan. 2021.

DIAS, Érika \& PINTO, Fátima (2019). Educação e Sociedade. Ensaio: Avaliação $e$ Políticas Públicas em Educação, Rio de Janeiro, v. 27, n. 104, p. 449-455, set. Disponível em: https://doi.org/10.1590/s0104-40362019002701041. Acesso em nov. 2019.

DUSSEL, Inês (2020). A escola na pandemia: reflexões sobre a escola em tempos deslocados. Práxis Educativa. Ponta Grossa, v. 15, p.1-16, jul. Disponível em: https://revistas2.uepg.br/index.php/praxiseducativa/article/view/16482. Acesso em: mar. 2021. 
FERREIRA, Luciana Haddad \& BARBOSA, Andreza (2020). Lições de Quarentena: limites e possibilidades da atuação docente em época de isolamento social. Práxis Educativa. Ponta Grossa, v. 15, p. 1-24, jul. Disponível em: https://revistas2.uepg.br/index.php/praxiseducativa/article/view/15483. Acesso em: mar. 2021.

FIOCRUZ (2020). Nota Técnica $\mathrm{n}^{\circ}$ 1/2020/PG-EBS/IOC-FIOCRUZ. Nota técnica em que o Instituto Oswaldo Cruz (IOC/Fiocruz) orienta ações de gestores e profissionais da educação para a reestruturação do espaço escolar no contexto do pós-pandemia de Covid-19. FIOCRUZ, 31 julho. Disponível em: $<$ http://www.fiocruz.br/ioc/media/nota_tecnica_n01_2020_pgebs_ioc_fiocruz.pdf $>$. Acesso em: ago. 2020.

G1. (s.d.). Defensoria diz que mais da metade dos alunos do RJ enfrentam problemas de acesso à internet: Pesquisa da instituição constatou que um em cada dois alunos (49\%) precisa compartilhar o uso do aparelho eletrônico para estudar. Globo.com, Seção Rio de Janeiro, Rio de Janeiro, 30 set. 2020. Disponível em: <https://g1.globo.com/rj/rio-de-janeiro/noticia/2020/09/30/defensoria-diz-quemais-da-metade-dos-alunos-do-rj-enfrentam-problemas-de-acesso-a-internet. ghtml>. Acesso em dez. 2020.

JHU, Johns Hopkings University \& Medicine (2021). Covid-19 Map - Johns Hopkins Coronavirus Resource Center. Disponível em: <https://coronavirus .jhu.edu/map.html>. Acesso: jan. 2021.

KENSKI, Vani Moreira (2015). Educação e tecnologias: o novo ritmo da informação. Campinas: Papirus editora.

LIMA, Danilo et al. (2020). Covid-19 no Estado do Ceará: Comportamentos e crenças na chegada da pandemia. Ciência e Saúde Coletiva. Abril. Disponível em: _ _ _http://www.cienciaesaudecoletiva.com.br/artigos/covid19-no-estado-doceara-compo rtamentos-e-crencas-na-chegada-da-pandemia/17540?id=17540>. Acesso em: dez. 2020.

MARCONI, Marina de Andrade; LAKATOS, Eva Maria (2010). Fundamentos de metodologia científica. São Paulo: Editora Atlas.

MENDES, Fábio Ribeiro (2013). Meu filho não quer estudar. Porto Alegre: Autonomia editora.

MORAN, José Manuel; MASETTO, Marcos Tarciso \& BEHRENS, Marilda Aparecida (2001). Novas tecnologias e mediação pedagógica. São Paulo: Papirus.

MOREIRA, Lisandra et al. (2020). Mulheres em tempos de pandemia: um ensaio teóricopolítico sobre a casa e a guerra. Revista Psicologia e Sociedade, 32, p. 01-19. Disponível em: <https://www.scielo.br/pdf/psoc/v32/1807-0310-psoc-32e020014.pdf>. Acesso: dez. 2021.

OMS. Organização Mundial da Saúde. Folha Informativa - COVID-19 (doença causada pelo novo coronavírus). Disponível em: < https://www.paho.org/pt/topicos/coronavirus/doenca-causada-pelo-novo-coronavi rus-covid-19>. Acesso em: jul. 2020.

PEREIRA, Mara Dantas et al. (2020). A pandemia de COVID-19, o isolamento social, consequências na saúde mental e estratégias de enfrentamento: uma revisão integrativa. Revista Research, Society and Development. Jun. Disponível em: $<$ (PDF) A pandemia de COVID-19, o isolamento social, consequências na saúde mental e estratégias de enfrentamento: uma revisão integrativa (researchgate.net) $>$. Acesso: jan. 2021.

PEREIRA, Hortência Pessoa; SANTOS, Fábio Viana \& MANENTI, Mariana Aguiar (2020). Saúde mental de docentes em tempos de pandemia: os impactos das 
atividades remotas. Boletim de Conjuntura (BOCA), Boa Vista, v. 3, n. 9, p. 26-32, ago. ISSN 2675-1488. Disponível em: $<$ https://revista.ufrr.br/boca/article/view/Pereiraetal >. Acesso em: 08 feb. 2021. doi:http://dx.doi.org/10.5281/zenodo.3986851.

RAMÍREZ-ORTIZ, Jairo et al. (2020). Consecuencias de la pandemia COVID-19 en la Salud Mental asociadas al aislamiento social. SciELO Preprints, 1, 1-21. Disponível em: <https://preprints.scielo.org/index.php/scielo/preprint/view/303/ 358>. Acesso em: jan. 2021.

REIS-FILHO, José Amorim \& QUINTO, Danilo (2020). COVID-19, social isolation, artisanal fishery and food security: how these issues are related and how important is the sovereignty of fishing workers in the face of the dystopian scenario. SciELO Preprints, 1-26. Disponível em: https://preprints.scielo.org/index.php /scielo/preprint/view/54. Acesso em: fev. 2021

SANTOS, Boaventura de Sousa (2020). A cruel pedagogia do vírus. Edições Almedina S.A. Coimbra: Portugal.

SELIGMANN-SILVA, E. (2013). Psicopatologia no trabalho: aspectos contemporâneos. In: FERREIRA, Januário Justino \& PENIDO, Laís de Oliveira. Saúde mental no trabalho: coletânea do fórum de saúde e segurança no trabalho do estado de Goiás. Goiânia: Cir Gráfia.

SZYMANZKI, Heloisa (2003). A relação família/escola: desafios e perspectivas. Brasília: Plano Editora.

TARDIF, Maurice \& LESSARD, Claude (2014). O trabalho docente: elementos para uma teoria da docência como profissão de interações humanas. Petrópolis: Vozes.

TOKARNIA, Mariana (2020). Brasil tem 4,8 milhões de crianças e adolescentes sem internet em casa. Agência Brasil, Seção Educação, Rio de Janeiro, 17 maio. Disponível em: <https://agenciabrasil.ebc.com.br/educacao/noticia/2020-05/brasiltem-48-milhoes-de-criancas-e-adolescentes-sem-internet-em-casa $>$. Acesso em: dez. 2020.

UNESCO (2020). A Comissão Futuros da Educação da Unesco apela ao planejamento antecipado contra o aumento das desigualdades após a covid-19. Paris: Unesco, 16 abr. Disponível em: <https://pt.unesco.org/news/comissao-futuros-da-educacaoda-unesco-apela-ao-planejamento-antecipado-o-aumento-das $>$. Acesso em jan. 2021.

WHO. World Health Organization (2020). Q\&A on coronaviruses (COVID-19). Disponível em: <https://www.who.int/emergencies/diseases/novel-coronavirus2019/question-and -answers-hub>. Acesso em: jan. 2021.

Artigo recebido em: 04 de julho de 2021.

Aprovado em: 25 de novembro de 2021.

DOI: 10.12957/intellectus.2021.60921 